Article

\title{
Post Synthetic Defect Engineering of UiO-66 Metal-Organic Framework with An Iridium(III)-HEDTA Complex and Application in Water Oxidation Catalysis
}

\author{
Giordano Gatto, Alceo Macchioni *(1), Roberto Bondi, Fabio Marmottini and \\ Ferdinando Costantino * (D) \\ Department of Chemistry, Biology and Biotechnology, Università di Perugia and CIRCC, Via Elce di Sotto, 8, \\ I-06123 Perugia, Italy; giordano.gatto@libero.it (G.G.); robertobondi11@gmail.com (R.B.); \\ fabio.marmottini@unipg.it (F.M.) \\ * Correspondence: alceo.macchioni@unipg.it (A.M.); ferdinando.costantino@unipg.it (F.C.); \\ Tel.: +39-075-585-5579 (A.M.); +39-075-585-5563 (F.C.)
}

Received: 9 August 2019; Accepted: 5 October 2019; Published: 10 October 2019

\begin{abstract}
Clean production of renewable fuels is a great challenge of our scientific community. Iridium complexes have demonstrated a superior catalytic activity in the water oxidation (WO) reaction, which is a crucial step in water splitting process. Herein, we have used a defective zirconium metal-organic framework (MOF) with UiO-66 structure as support of a highly active Ir complex based on EDTA with the formula [Ir(HEDTA)Cl]Na. The defects are induced by the partial substitution of terephthalic acid with smaller formate groups. Anchoring of the complex occurs through a post-synthetic exchange of formate anions, coordinated at the zirconium clusters of the $\mathrm{MOF}$, with the free carboxylate group of the $[\operatorname{Ir}(\mathrm{HEDTA}) \mathrm{Cl}]^{-}$complex. The modified material was tested as a heterogeneous catalyst for the WO reaction by using cerium ammonium nitrate (CAN) as the sacrificial agent. Although turnover frequency (TOF) and turnover number (TON) values are comparable to those of other iridium heterogenized catalysts, the MOF exhibits iridium leaching not limited at the first catalytic run, as usually observed, suggesting a lack of stability of the hybrid system under strong oxidative conditions.
\end{abstract}

Keywords: metal-organic framework; post-synthetic modification; iridium catalysis; water oxidation; water splitting

\section{Introduction}

Water oxidation (WO) to molecular oxygen is considered the ideal reaction to provide electrons and protons for the generation of renewable fuels [1-3]. In addition to being thermodynamically disfavored, WO is also an extremely complicated, multi-electron and multi-proton reaction from the kinetic point of view, asking for an efficient and robust catalyst [4]. WOCs (water oxidation catalysts) based on iridium are among the most efficient reported in the literature so far, having, however, in the little abundance and, consequently, high cost of iridium their "Achilles' heel" [5-7]. A possible strategy to alleviate this problem stems in the minimization of the amount of noble-metal exploited in the catalytic process, according to the noble-metal atom economy principle [5]. This can be accomplished by utilizing (i) extremely active molecular catalysts at very low concentration [8-15], (ii) layered heterogeneous catalyst in which almost all active sites are reachable by the substrate [16], and (iii) heterogenized hybrid materials derived from the anchoring of a well-defined molecular catalyst on a suitable support $[17,18]$. The latter strategy should guarantee a very high percentage of active 
sites (potentially 100\%), increased robustness of catalyst, mainly due to the inhibition of associative deactivation processes, and possible beneficial cooperation between the anchored catalyst and support. Many hybrid heterogenized catalysts have been reported in the literature [17,19-23] and, among them, those using MOF as support, pioneered by Lin and co-workers [24,25], have been particularly successful [26]. MOFs are a class of porous crystalline compounds constituted by the ordered connection of metal clusters and organic linkers, forming accessible pores and channels potentially useful for a plethora of applications, especially in catalysis and energy production [27-29], as support for metal nanoparticles [30] and for enhanced gas sorption properties [31]. Some of them are rapidly approaching the industrial world [32]. Zr-MOFs are particularly interesting for their chemical and thermal stability and low production cost. The archetype structure is that of UiO-66 which is constituted of hexanuclear clusters with the formula $\mathrm{Zr}_{6} \mathrm{O}_{4}(\mathrm{OH})_{4}(\mathrm{BDC})_{6}(\mathrm{BDC}=1$,4-benzenedicarboxylic acid) in a cubic framework with face-centered cubic (fcu) topology [33]. UiO-66, together with other Zr-MOFs with different topologies, such as NU-1000, was already employed as support for Ir-based catalytic complex, employing both the Zr-cluster site [34,35] and via post-synthetic modification of the ligands for the in situ formation of the complex [36]. UiO-66 possess the exotic feature to be defective when it is crystallized in the presence of a mono carboxylic modulator such as formic, acetic, or benzoic acid, which act as substituent of BDC linker attached to the $\mathrm{Zr}_{6}$ cluster thus inducing missing linker or missing cluster defects into the structure. These defects can be considered as an opportunity to be employed for imparting targeted functionality to the MOFs by means the so called post-synthetic defect exchange (PSDE) of the monocarboxylic groups with other carboxylic linkers [37,38].

Herein, we report on the synthesis of formic acid (FA)-modulated UiO-66 with a high concentration of defects and its use a support for anchoring, by means of PSDE, an $\operatorname{Ir}(\mathrm{III})$ WOC complex based on EDTA $\left(E D T A=N, N, N^{\prime} N^{\prime}\right.$-ethylenediaminotetraacetic acid). The complex, of formula [Ir(HEDTA)Cl]Na (see Figure 1) was already reported in literature as an efficient and durable homogeneous WOC under chemical oxidation with CAN as a sacrificial agent [39]. The molecular structure of the complex clearly shows that it possesses a free carboxylic group which could be employed as an anchoring functionality for its deposition onto a solid surface. Our approach here consists in a PSDE of the FA-UiO-66 MOF with the $[\operatorname{Ir}(\mathrm{HEDTA}) \mathrm{Cl}]^{-}$complex dissolved in water. The anchoring occurred through a topotactic exchange of the coordinated FA with the carboxylic group of the IrCl-EDTA complex. The hybrid material (IrEDTA@UiO-66) was characterized by means of surface area and porosity studies, inductively coupled plasma-optical emission spetrometry (ICP-OES) analysis, nuclear magnetic resonance (NMR) spectroscopy, and tested for WO reaction by using CAN as the sacrificial agent. The hybrid exhibited WO activity with TOF and TON values comparable to those of the best performing materials. However, a significant Ir leaching was observed not only during the first catalytic run, as usually observed, suggesting that strong oxidative conditions with $\mathrm{Ce}^{4+}$ lead to a rapid decomposition of the hybrid material.<smiles></smiles>

Figure 1. Molecular structure of [Ir(HEDTA)Cl]Na complex. 


\section{Results and Discussion}

\subsection{Synthesis and Characterization}

Synthesis of FA-Modulated UiO-66

FA-modulated UiO-66 was prepared according to the procedure reported by Taddei et al. [38]. The use of a large amount of formic acid as modulator (100 eq. with respect to $\mathrm{Zr}$ ) induced the formation of a highly defective phase with respect to the defective free UiO structure, which can be obtained following other synthetic strategies present in literature [40]. FA acts as monocarboxylic modulator with the Zr clusters inducing two types of defects: missing linker defects (Figure 2b) and missing cluster defects (Figure 2c).

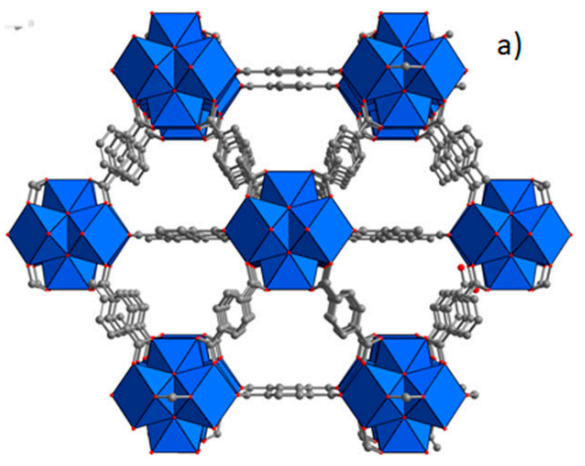

UiO-66 no defects

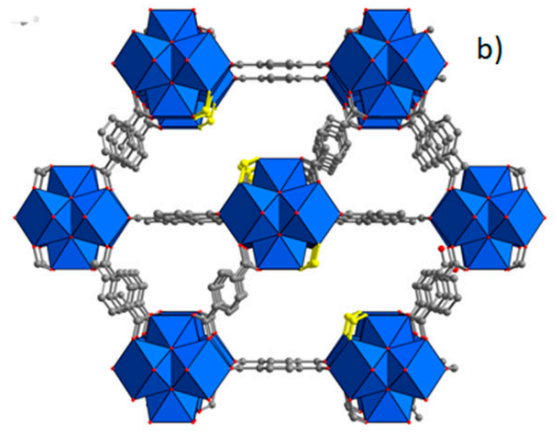

UiO-66_FA missing linkers

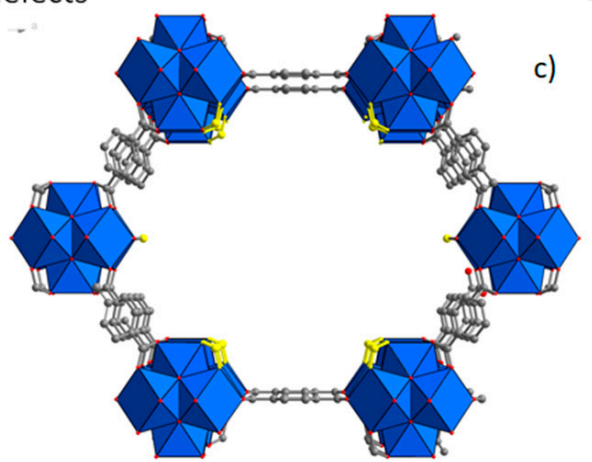

UiO-66_FA missing clusters

Figure 2. Structure of non-defective (a), missing linker defective (b), and missing cluster defective (c) UIO-66 phase. Formic acid is evidenced in yellow. Zirconium clusters are depicted in blue.

It is known that the materials obtained with FA as modulator most likely possess missing cluster defects [38]. Nitrogen adsorption and desorption analysis at $77 \mathrm{~K}$ was performed on FA-UiO-66 compound after activation at $120^{\circ} \mathrm{C}$ overnight. The $\mathrm{N}_{2}$ adsorption/desorption isotherm is reported in Figure $3 \mathrm{a}$ and the Brunauer-Emmett-Teller (BET) value is $1450 \mathrm{~m}^{2} / \mathrm{g}$ with a total micropore volume of $0.57 \mathrm{~cm}^{3} / \mathrm{g}$. These values, quite higher than the normal surface area and micropore volume of a defect-free UiO-66 (about $1100 \mathrm{~m}^{2} / \mathrm{g}$ and $0.4 \mathrm{~cm}^{3} / \mathrm{g}$ ), suggest the highly defective nature of the obtained material. X-ray powder diffraction (XRPD) pattern of FA_UiO-66 (Figure 3b) shows the peaks at $7.3^{\circ}$ and $8.5^{\circ}$ of $2 \theta$ belonging to the (111) and (200) of the fcu UiO-66 phase and a good crystallinity degree. ${ }^{1} \mathrm{H}-\mathrm{NMR}$ spectra on the hydrolyzed compound confirm the presence of a considerable amount of FA, as can be seen in Figure $3 \mathrm{~d}$. Integration of ${ }^{1} \mathrm{H}-\mathrm{NMR}$ signals belonging to FA (8.3 ppm) and BDC $(7.8 \mathrm{ppm})$ gives a FA/BDC ratio equal to 0.63 . The obtained solution after the hydrolysis of the sample with $\mathrm{NaOH}$ was analyzed with ion chromatography resulting in the following BDC and FA contents in the starting solid: $\mathrm{BDC}=2.78 \mathrm{mmol} / \mathrm{g}$ and $\mathrm{FA}=1.72 \mathrm{mmol} / \mathrm{g}$. 

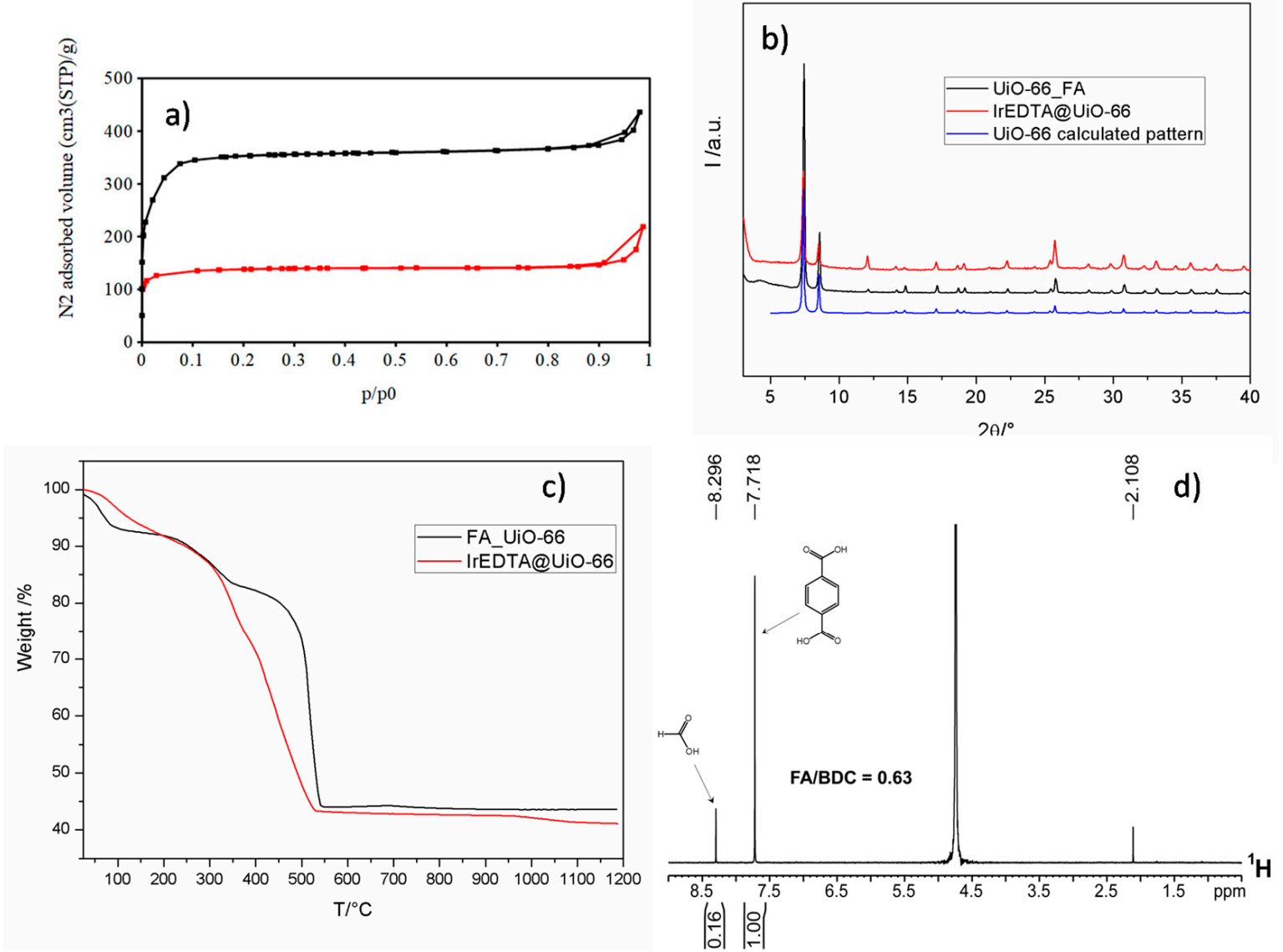

Figure 3. $\mathrm{N}_{2}$ adsorption and desorption isotherm for FA_UiO-66 (black line) and IrEDTA@UiO-66 (red line) (a). XRPD patterns of FA_UiO-66 (black), Ir-EDTA@UiO-66 (red), and calculated pattern for UiO-66 (blue) (b). TGA curve for FA_UiO-66 (black) and IrEDTA@UiO-66 (red) (c) and ${ }^{1} \mathrm{H}-\mathrm{NMR}$ spectrum for hydrolyzed FA_UiO-66 MOF (NaOD/D 20 , 298 K) (d).

Given these results, the ratio $\mathrm{FA} / \mathrm{BDC}=0.63$ is in very good agreement with the results of NMR experiments. Since FA is a monocarboxylic acid, the following equation can be used in order to determine the formula of the defective MOF:

$$
\frac{F A}{B D C}=\frac{2 x}{6-x}=0.62
$$

resulting in $\mathrm{Zr}_{6} \mathrm{O}_{4}(\mathrm{OH})_{4}(\mathrm{BDC})_{4.58}(\mathrm{FA})_{2.74}$. Thermogravimetric analysis (Figure 3c) shows three different weight losses at $100{ }^{\circ} \mathrm{C}(7.5 \%), 330{ }^{\circ} \mathrm{C}(11 \%)$, and $540{ }^{\circ} \mathrm{C}(38 \%)$ due to the loss of water molecules and decomposition of the organic part of the MOF. If the plateau in the $550-1200{ }^{\circ} \mathrm{C}$ temperature range is assumed to be $6 \mathrm{ZrO}_{2}(\mathrm{Mw}=123 \mathrm{~g} / \mathrm{mol})$, we can use this value as a reference $(100 \%)$ for extrapolating the theoretical formula from the analysis. The normalized weight at $100{ }^{\circ} \mathrm{C}$ is therefore $213 \%$. The experimental formula weight from TGA analysis at $100^{\circ} \mathrm{C}$ is, therefore, $1572 \mathrm{~g} / \mathrm{mol}$. Given the mass of the defective, desolvated MOF of formula $\mathrm{Zr}_{6} \mathrm{O}_{4}(\mathrm{OH})_{4}(\mathrm{BDC})_{4.58}(\mathrm{FA})_{2.74}=1555 \mathrm{~g} / \mathrm{mol}$, this is in good agreement with the experimental data from TGA analysis. The PSDE process for anchoring the Ir-EDTA complex onto the cluster surface is shown in Figure S3. After soaking the evacuated MOF into a water solution containing the dissolved complex $(0.02 \mathrm{M})$ and heating at $80^{\circ} \mathrm{C}$ for $24 \mathrm{~h}$, the partial exchange of FA with the free carboxylic group of the complex occurred. Three samples with different amounts of exchanged Ir-EDTA were prepared: The compound was exchanged with 0.096, 0.077, and $0.057 \mathrm{mmol}$ of Ir-EDTA, respectively. ICP-OES analysis for the determination of Ir content gave the following results: IrEDTA@UiO-66(1)= $256 \mu \mathrm{mol} / \mathrm{g}$; IrEDTA@UiO-66(2)= $226 \mu \mathrm{mol} / \mathrm{g}$; and IrEDTA@UiO-66(3)=170 $\mu \mathrm{mol} / \mathrm{g}$. Figure 3a shows the nitrogen adsorption and desorption analysis 
at $77 \mathrm{~K}$ performed in the same conditions on IrEDTA@UiO-66 containing $256 \mu \mathrm{mol} / \mathrm{g}$ (red curve). After the exchange the calculated BET value is reduced to $547 \mathrm{~m}^{2} / \mathrm{g}$ and the total micropore volume is reduced to $0.22 \mathrm{~cm}^{3} / \mathrm{g}$ suggesting that the complex is not simply linked to the particle surface but most likely occupies the micropores created by the defects. However, the Ir-EDTA complex is inserted in the micropores and the complex could obstruct a part of the micropore volume of the substrate. TGA analysis of IrEDTA@UiO-66 (Figure 3b, red curve) is similar to that of the pristine MOF although the decomposition of the material starts at lower temperature (around $350{ }^{\circ} \mathrm{C}$ ) with respect to the unmodified MOF.

The XRPD patterns of the three samples are shown in Figure 4. Anchoring Ir-EDTA onto the cluster surface did not affect the structure of the MOF since the characteristic peaks remained unaltered.

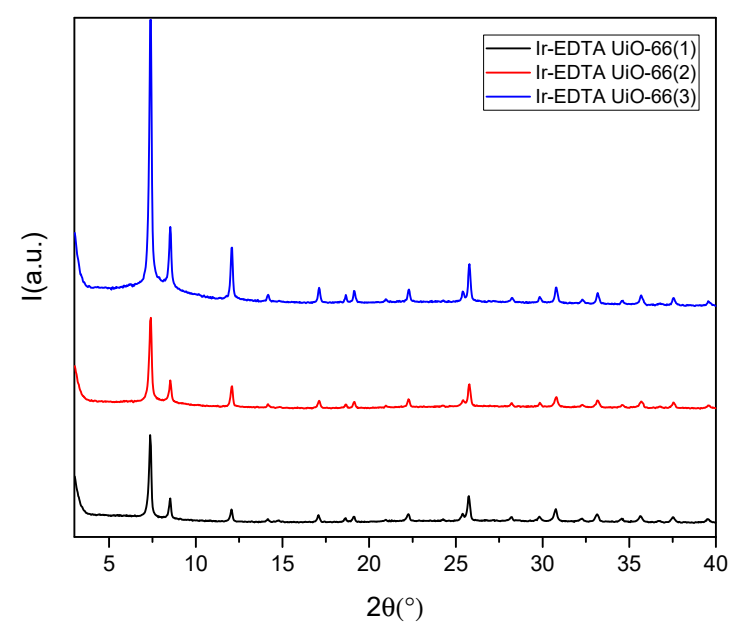

Figure 4. XRPD pattern of IrEDTA@UiO66(1) black, (2) red and (3) blue.

Figure 5 shows the ${ }^{1} \mathrm{H}-\mathrm{NMR}$ spectrum of the hydrolyzed IrEDTA@UiO-66 sample. The peak at $8.3 \mathrm{ppm}$ attributed to FA exhibits a reduced intensity and the integration with that of BDC gave as result $\mathrm{FA} / \mathrm{BDC}=0.10$. This value is about six times lower than the unmodified defective MOF (FA/BDC $=0.63$ ) meaning that the most part of FA was successfully exchanged by Ir-EDTA complex. Peaks belonging to the Ir-EDTA complex are clearly visible at 3 and $2.2 \mathrm{ppm}$. With this new ratio, a suggested formula can be $\mathrm{Zr}_{6} \mathrm{O}_{4}(\mathrm{OH})_{4}(\mathrm{BDC})_{4.58}(\mathrm{FA})_{0.6}(\mathrm{Ir}-\mathrm{EDTA})_{2.2}$.

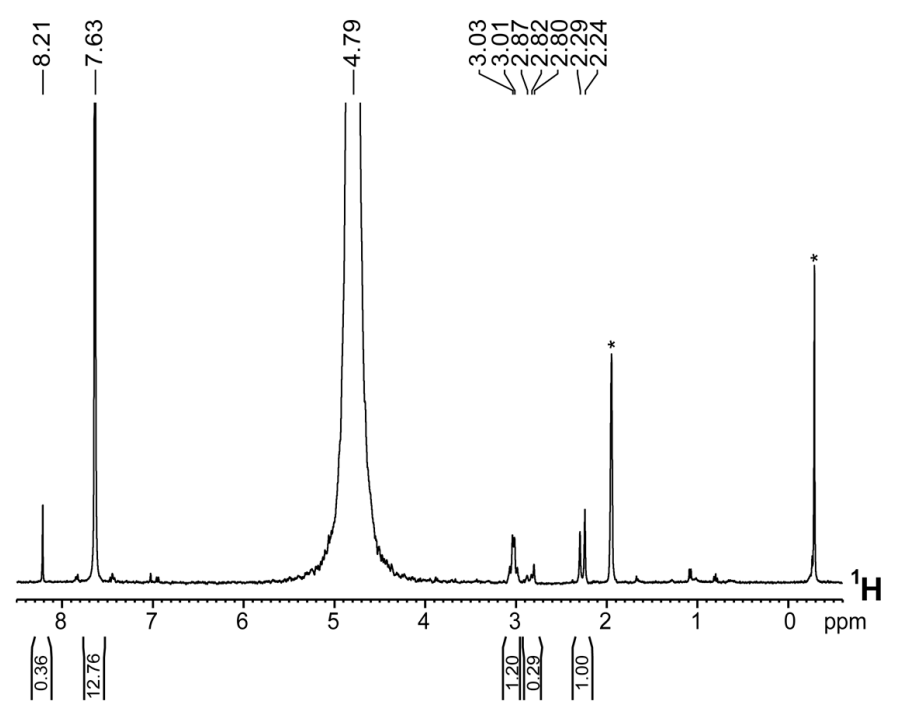

Figure 5. ${ }^{1} \mathrm{H}-\mathrm{NMR}$ spectrum of hydrolyzed Ir@UiO-66(1) sample [NaOD/D $2 \mathrm{O}, 298 \mathrm{~K}$; ${ }^{*}$ denote impurities present in the solvent, likely acetone (ca. 2 ppm) and Silicon Grease (slightly lower than 0 ppm)]. 


\subsection{Water Oxidation Catalytic Activity of IrEDTA@UiO-66}

Herein, the catalytic activity of IrEDTA@UiO-66 hybrid materials toward water oxidation to molecular oxygen (Equation (1)) is described. First, a blank experiment by using only the FA_UiO-66 without Ir was performed by adding a $25 \mathrm{mM}$ solution of CAN to $3 \mathrm{mg}$ of MOF (see Figures S1 and S2). No oxygen evolution was observed confirming the inactivity of MOF toward water oxidation. Catalytic tests with Ir containing MOF were carried out by using $\mathrm{Ce}^{4+}$ (added as CAN) as a sacrificial oxidant, dispersing the proper amount of catalyst in acidic water $\left(\mathrm{pH} 1,0.1 \mathrm{M} \mathrm{HNO}_{3}\right)$ at $25^{\circ} \mathrm{C}$.

$$
4 \mathrm{Ce}^{4+}+2 \mathrm{H}_{2} \mathrm{O} \rightarrow 4 \mathrm{Ce}^{3+}+4 \mathrm{H}^{+}+\mathrm{O}_{2}
$$

The evolved gas, according to Equation (1), was quantified by differential manometry (See Materials and Methods). In a first series of experiments, a consecutive triple addition (100, 150, and $500 \mu \mathrm{L})$ of a 1.25 M solution of CAN to $4.9 \mathrm{~mL}$ of a $51.5 \mu \mathrm{M}$ IrEDTA@UiO-66 suspension was executed (Table 1, entries 1-3; Figure 6). IrEDTA@UiO-66 was found to be a competent catalyst for water oxidation and exhibited a TOF of ca. $5 \mathrm{~min}^{-1}$ and TON values included between 62 and 308 with yields $=30 \%-50 \%$. A second series of measurements was performed with the aim of evaluating possible leaching of the molecular catalyst from the MOF support. Particularly, a catalytic run was executed by using 73.12 $\mu \mathrm{M}$ IrEDTA@UiO-66 and 75 mM CAN (Table 1, entry 4). At the end of $\mathrm{O}_{2}$ evolution IrEDTA@UiO-66 was recovered by filtration and the supernatant solution tested by the addition of another aliquot of 75 mM CAN (Table 1, entry 5). Moreover, the recovered solid was tested under the same conditions (Table 1, entry 6). At the end of the reaction the solid catalyst was again recovered by filtration and the second supernatant tested (Table 1 , entry 7$)$. The measured TOF $\left(4 \mathrm{~min}^{-1}\right)$ and TON $(108$, yield $=42 \%)$ values of the starting IrEDTA@UiO-66 are nicely consistent with those observed in the first series of experiments. Furthermore, the recovered solid IrEDTA@UiO-66 exhibits similar TOF (6 min $\left.{ }^{-1}\right)$ and TON $(180$, yield $=67 \%)$ values. Nevertheless, the two supernatants are active, with even higher TOF (10 and $13 \mathrm{~min}^{-1}$ ) but comparable TON (363, yield $=44 \%$ and 1013 , yield $=46 \%$ ) values, evidencing some leaching of iridium in solution. ICP-OES measurements indicate that $30.98 \%$ and $30.75 \%$ of iridium leached out from IrEDTA@UiO-66 after the first and second catalytic run, respectively. In order to check the stability of the MOF before catalysis we evaluated the Ir leaching by dispersing IrEDTA@UiO-66 in a $0.1 \mathrm{M} \mathrm{HNO}_{3}$ solution for $2 \mathrm{~h}$, without the addition of CAN. The measured Ir leaching was about 35\%, which is similar to that observed in the first catalytic run. It means that the grafted complex is scarcely stable upon acidic conditions. The catalytic activity of IrEDTA@UiO-66 compares well with those of the molecular precursor [34] and hybrid material IrEDTA@ $\mathrm{TiO}_{2}$ [20], tested under similar conditions, in terms of TOF (Table 1, entries 8-10 and 12). The TON values are clearly lower than those observed for the molecular precursor, which provide $100 \%$ yield, and somewhat smaller also than those of IrEDTA@ $@ \mathrm{TiO}_{2}$ (Table 1, entries 8-10 and 12). Nevertheless, the main criticality of IrEDTA@UiO-66 seems to be the leaching of iridium, occurring also after the second catalytic run, contrary to what observed for IrEDTA@ $\mathrm{TiO}_{2}$ (Table 1, entries 11 and 13) and other heterogenized iridium catalysts reported before $[17,20]$. Several explanations might be provided for such a phenomenon. It can be hypothesized some $\mathrm{Ce}^{4+}$ might undergo an exchange with the $\mathrm{Zr}^{4+}$ ions of MOF, becoming not available anymore for driving the oxidative splitting of water. Alternatively, it might be hypothesized that the oxidative potential of iridium inIrEDTA@UiO-66 is slightly higher than in the molecular precursor and hybrid material IrEDTA@TiO ${ }_{2}$, thus asking for a higher $\mathrm{Ce}^{4+} / \mathrm{Ce}^{3+}$ ratio in order to reach the appropriate "Nernstian" potential for WO [41,42]. Both the explanations are consistent with the observation that the addition of a second aliquot of CAN restores the catalytic activity. 
Table 1. Summary of the water oxidation (WO) catalytic data for Equation (1). "Sur" indicates supernatant.

\begin{tabular}{|c|c|c|c|c|c|c|c|}
\hline \multirow{2}{*}{ Entry } & \multirow{2}{*}{ Catalytic Run } & {$[\mathrm{Ir}]$} & [CAN] & $\mathrm{d}\left[\mathrm{O}_{2}\right] / \mathrm{dt}$ & TOF & TON & Yield \\
\hline & & $\mu \mathbf{M}$ & $\mathrm{mM}$ & $\mathrm{mM} / \mathrm{min}$ & $\min ^{-1}$ & & $\%$ \\
\hline \multicolumn{8}{|c|}{ IrEDTA@UiO-66 } \\
\hline 1 & Run I & 50 & 25 & 0.23 & 5 & 67 & 54 \\
\hline 2 & Run II & 49 & 38 & 0.19 & 4 & 32 & 33 \\
\hline 3 & Run III & 45 & 126 & 0.29 & 6 & 382 & 55 \\
\hline 4 & Run I & 73 & 75 & 0.31 & 4 & 108 & 42 \\
\hline 5 & Sur I & 23 & 75 & 0.22 & 10 & 363 & 44 \\
\hline 6 & Run II & 70 & 75 & 0.41 & 6 & 180 & 67 \\
\hline 7 & Sur II & 9 & 75 & 0.11 & 13 & 1013 & 46 \\
\hline \multicolumn{8}{|c|}{ IrEDTA [39] } \\
\hline 8 & Run I & 5 & 80 & & 7 & 4000 & 100 \\
\hline 9 & Run II & 5 & 20 & & 7 & 1000 & 100 \\
\hline \multicolumn{8}{|c|}{ 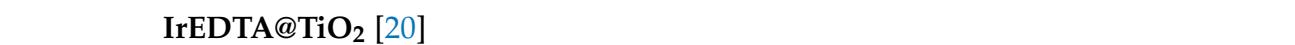 } \\
\hline 10 & Run I & 35 & 9 & & 4 & 46 & 70 \\
\hline 11 & Sur I & 10 & 9 & & 7 & 141 & 59 \\
\hline 12 & Run II & 25 & 9 & & 4 & 78 & 83 \\
\hline 13 & Sur II & 0 & 10 & & - & - & - \\
\hline 14 & \multicolumn{7}{|l|}{ IrCp*@Zr-bpy-dc [25] } \\
\hline 15 & Run I & 10 & 3 & & 0.52 & & 17 \\
\hline 16 & Run II & 10 & 3 & & 0.54 & & 17 \\
\hline 17 & Run III & 10 & 3 & & 0.53 & & 17 \\
\hline 18 & \multicolumn{7}{|l|}{ IrCp*@Zr-ppy-dc [25] } \\
\hline 19 & Run I & 10 & 3 & & 6.3 & & 27 \\
\hline 20 & Run II & 10 & 3 & & 9.4 & & 80 \\
\hline
\end{tabular}

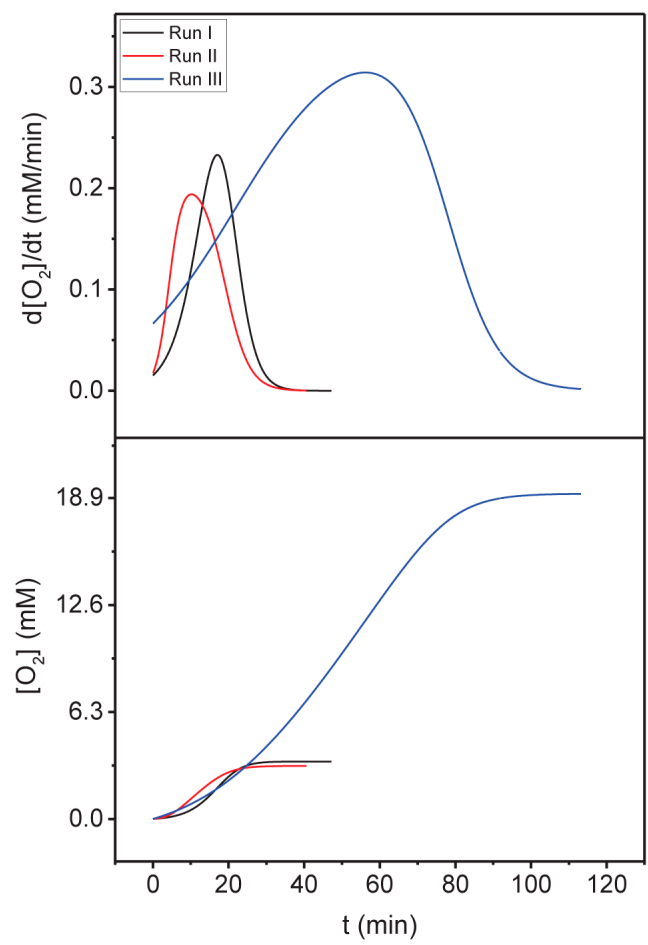

Figure 6. $\left[\mathrm{O}_{2}\right]$ (bottom) and $\mathrm{d}\left[\mathrm{O}_{2}\right] / \mathrm{dt}(\mathbf{u p})$ versus time trends for a WO triple cerium ammonium nitrate (CAN) addition experiment (Table 1, entries 1-3).

A catalytic run with a large amount of IrEDTA@UiO-66 (50 mg, $2.61 \mathrm{mM}$; CAN = $75 \mathrm{mM})$ was performed in order to recover and analyze IrEDTA@UiO-66 post-catalysis. The ${ }^{1} \mathrm{H}-\mathrm{NMR}$ spectrum of the recovered solid digested in $\mathrm{NaOD}$ is significantly different than that before catalysis (Figure 7). 
In particular, the typical resonances of the $-\mathrm{CH}_{2}$ protons of EDTA in the 2.0-3.2 ppm range are not visible anymore in the post-catalysis sample, suggesting a complete degradation of the ligand framework [43]. XRPD pattern of the MOF after three catalytic runs (Figure S4) shows no crystallinity loss. The FA/BDC ratio (Figure S5) post catalysis is 0.20 suggesting that the framework remained most likely unaltered and the degradation involved a small fraction of BDC together with the Ir-EDTA complex. However, because the recovered solid is still active in $\mathrm{WO}$, it might be hypothesized that after EDTA degradation some iridium remains attached at the MOF structure, possibly through the formation of $\mathrm{Zr}-\mathrm{O}-\mathrm{Ir}$ oxo bridges, as observed in heterogenized WOCs prepared by anchoring an Ir-Kläui molecular precursor onto $\mathrm{BiVO}_{4}$ nanopyramids [17].

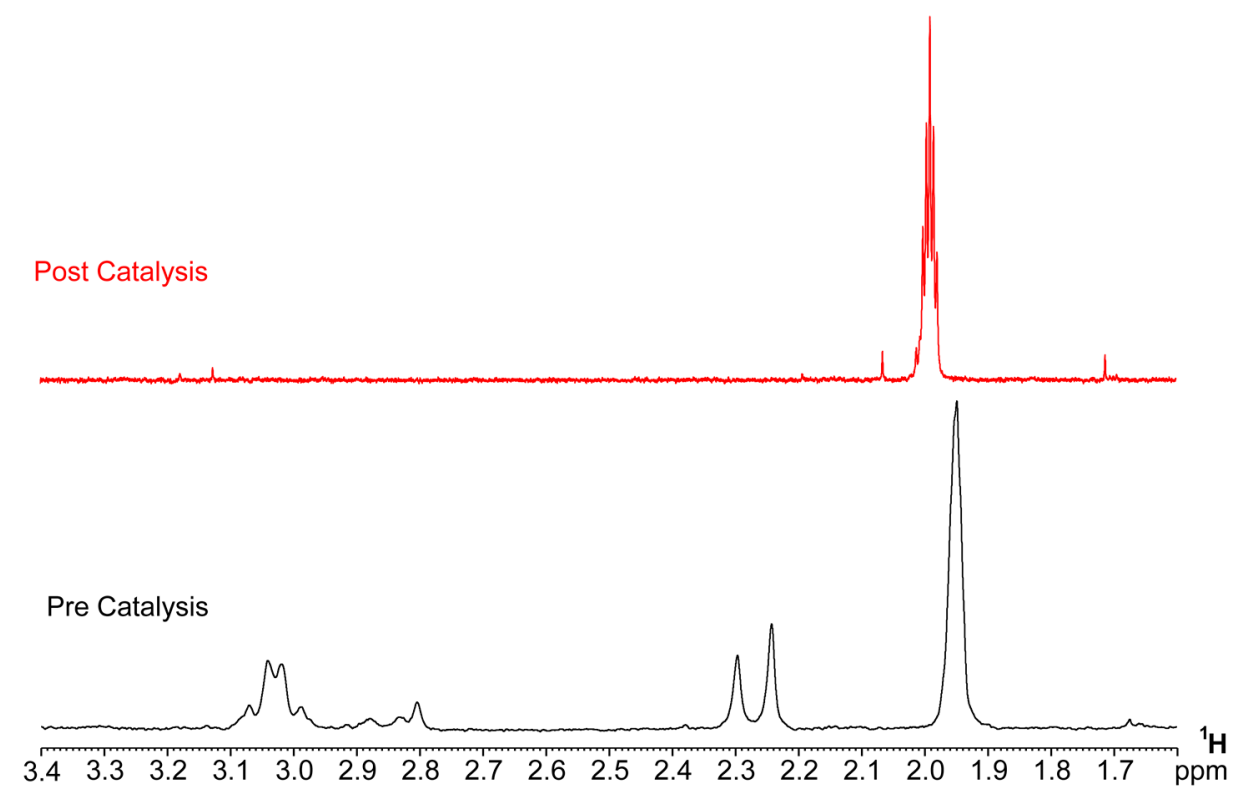

Figure 7. ${ }^{1} \mathrm{H}-\mathrm{NMR}$ spectra $\left(\mathrm{NaOD} / \mathrm{D}_{2} \mathrm{O}, 298 \mathrm{~K}\right)$ before (bottom) and after (up) a catalytic run, showing the disappearance of the aliphatic resonance of the EDTA ligand at 2.2-3.2 ppm.

\section{Materials and Methods}

\subsection{Synthetic Procedures}

All reagents were used as received without further purification: $\mathrm{ZrCl}_{4}$, cerium ammonium nitrate (CAN), formic acid (FA), terephthalic acid (BDC) and $N, N$-dimethylformamide (DMF) was purchased from Sigma Aldrich (St. Louis, MO, USA). [Ir(HEDTA)Cl]Na was prepared according to Reference [34].

\subsubsection{Synthesis of FA-UiO-66}

$\mathrm{ZrCl}_{4}(0.60 \mathrm{~g}, 2.5 \mathrm{mmol})$ was dissolved in DMF $(40 \mathrm{~mL})$. Then, water $(0.135 \mathrm{~mL}, 7.5 \mathrm{mmol})$, FA $(9.4 \mathrm{~mL}, 250 \mathrm{mmol})$, and BDC $(0.435 \mathrm{~g}, 2.5 \mathrm{mmol})$ were added to the solution. The mixture was sonicated until complete dissolution and divided in four vials $(10 \mathrm{~mL}$ each) and heated in an oven at $120{ }^{\circ} \mathrm{C}$ for $16 \mathrm{~h}$. After the reaction, the solid was recovered for centrifugation and washed with DMF (one time after $2 \mathrm{~h}$ soaking), water ( $2 \mathrm{~h}$ soaking), and acetone (one time after $10 \mathrm{~min}$ soaking). At the end, the solid was dried in an oven at $80^{\circ} \mathrm{C}$ for $2 \mathrm{~h}$.

\subsubsection{Synthesis of IrEDTA@UiO-66 via PSDE}

FA_UiO66 (60 mg) was suspended in $5 \mathrm{~mL}$ of a $0.02 \mathrm{M}$ water solution of a [ $\operatorname{Ir}(\mathrm{HEDTA}) \mathrm{Cl}] \mathrm{Na}$ $(0.02 \mathrm{M})$ for $24 \mathrm{~h}$ at $80^{\circ} \mathrm{C}$. After completion of the reaction, the solid was centrifuged and washed with DMF (one time, two-hour soaking), water (two times, two-hour soaking), and acetone (two times, two-hour soaking). The solid was dried in an oven at $80^{\circ} \mathrm{C}$ for two hours. Two other syntheses with 
different Ir contents were carried out: $30 \mathrm{mg}$ of UiO-66 in $0.01 \mathrm{M}$ Ir-EDTA solution (5 mL) and $40 \mathrm{~g}$ in 0.015 Ir-EDTA solution (5 mL).

\subsection{Analytical and Instrumental Procedures}

Powder X-Ray Diffraction (PXRD). PXRD patterns were collected in reflection geometry in the $4-40^{\circ}$ $2 \theta$ range, with a 40 s per step counting time and with a step size of $0.016^{\circ}$ on a PANalytical X'PERT PRO diffractometer (Malvern Panalytical Ltd., Malvern, UK), PW3050 goniometer, (Malvern Panalytical Ltd., Malvern, UK) equipped with an X'Celerator detector (Malvern Panalytical Ltd., Malvern, UK) by using the $\mathrm{Cu}-\mathrm{K} \alpha$ radiation. The long fine focus (LFF) ceramic tube operated at $40 \mathrm{kV}$ and $40 \mathrm{~mA}$.

Thermogravimetric analysis (TGA). TGA was performed using a Netzsch STA490C thermoanalyzer (NETZSCH Group, Selb, Germany) under a $20 \mathrm{~mL} \mathrm{~min}^{-1}$ air flux with a heating rate of $10{ }^{\circ} \mathrm{C} \mathrm{min}-1$.

Nitrogen adsorption and desorption isotherms. $\mathrm{N}_{2}$ adsorption/desorption isotherms were performed using a Micromeritics ASAP 2010 analyzer (Micromeritics, Norcross, GA, USA). Prior of the analysis, the samples were degassed overnight under vacuum at $120^{\circ} \mathrm{C}$. BET analysis and t-plot analysis of the adsorption data were used to calculate specific surface area and micropore volume respectively. The Harksin and Jura equation was used as reference for the statistical thickness calculation.

Ion-Chromatography Analysis. Ion chromatography was carried out using a Dionex 500 (Dionex Corp., Sunnyvale, CA, USA) apparatus with a CD20 suppressed conductivity module. Sample analysis was performed as follow: About $30 \mathrm{mg}$ of sample was dispersed in $40 \mathrm{~mL}$ of $\mathrm{NaOH} 0.0125 \mathrm{M}$ and refluxed for $2 \mathrm{~h}$. After reflux, the solution was diluted to $100 \mathrm{~mL}$ by water. The resulting solution was analyzed by ion chromatography using a Dionex AS11 column and eluted with a flux of $1.5 \mathrm{~mL} / \mathrm{min}$ with $\mathrm{NaOH} 6 \mathrm{mM}$ in the case of $\mathrm{BDC}$ analysis or $\mathrm{NaOH} 0.1 \mathrm{mM}$ in the case of FA analysis.

ICP-OES Analysis. The ICP-OES analysis was carried out using a Varian 700-ES series (Agilent Technologies, Santa Clara, CA, USA) with a standard (2,5,7, and $10 \mathrm{mg} / \mathrm{L}$ respectively) of Iridium solution.

WO catalytic experiments. Catalytic experiments were performed using two homemade jacketed glass reactors coupled to a Testo 521-1 manometer. In a typical catalytic run, IrEDTA@UiO-66 suspended in a $0.1 \mathrm{M} \mathrm{HNO}_{3}$ solution was loaded into the first reaction vessel (working cell), whereas an equal amount of neat water was loaded into the second one (reference cell). Both reactors were sealed with a rubber septum, connected to the manometer, kept at a constant temperature of $25^{\circ} \mathrm{C}$, and placed under stirring for $20 \mathrm{~min}$. Acquisition was started. When a steady baseline was achieved, an equal volume of a solution of CAN and neat water were injected into the working cell and reference cell, respectively, to reach a final volume of $5 \mathrm{~mL}$ in each reactor. The concentration of the stock solution of CAN was adjusted, depending on the final concentration desired, in order to have a maximum injection volume of $500 \mu \mathrm{L}$. The total gas evolved was estimated by measuring the differential pressure between the working and reference cell.

Fitting methodology and kinetic data analyses. All trends of $\left[\mathrm{O}_{2}\right]$ evolution versus time were fitted by a composite mathematical function developed by Peters and Baskin (PB) for distinguishing sigmoidal and bilinear growth profiles of plant roots [38]. The derivative of the $\mathrm{PB}$ fits provided reaction rate $\left(\mathrm{v}=\mathrm{d}\left[\mathrm{O}_{2}\right] / \mathrm{dt}\right)$ trends as function of time. Reaction rate over catalyst concentration led to TOF $(=\mathrm{v} /[\mathrm{Ir}])$, which was plotted versus the factor conversion $X\left(=4\left[\mathrm{O}_{2}\right] /[\mathrm{CAN}]_{0}\right)[9]$.

\section{Conclusions}

In this paper a catalytic active Ir complex based on EDTA was successfully anchored onto a defective Zr-MOF with UiO-66 structure. The post-synthetic modification of defective MOF for designing a new heterogenous catalyst was here validated for the first time demonstrating that substitution of small formate anions linked to zirconium clusters with a larger carboxylate-bearing complex is possible. The material was employed for water oxidation reaction using $\mathrm{Ce}^{4+}$ as the sacrificial agent. The catalyst showed a good catalytic activity, which is comparable to that observed for already reported iridium-supported Zr-MOF [25] and slightly lower than Ir-EDTA@TiO2 heterogenized 
catalysts [20]. However, Ir leaching occurs not only during the first catalytic run, as usually observed, but also for the successive ones. Moreover, leaching of Ir was also observed simply dispersing the solid in the nitric acid solution, without CAN addition. This fact suggests that the material is not stable under the acidic and strong oxidative conditions due to the high redox potential of $\mathrm{Ce}^{4+}$. Furthermore, the WO reaction yield is somewhat lower than that observed for other heterogenized iridium WOCs, indicating a possible exchange of the zirconium atom of MOF with cerium of CAN or a higher "Nernstian" potential. Despite those drawbacks, the results reported in this paper suggest that anchoring a molecular WOC onto a defective MOF is a viable strategy to assemble a hybrid material to be integrated into a device for the generation of renewable fuels. Future developments of this work will be devoted to the stability improvement of the system by performing photo- or electro-catalysis which avoid the use of $\mathrm{Ce}^{4+}$ and strong acidic conditions.

Supplementary Materials: The following are available online at http://www.mdpi.com/2304-6740/7/10/123/s1, Figure S1: Manometric oxygen evolution of IrEDTA@UiO-66 and UiO-66. Figure S2: Differential manometric oxygen evolution of IrEDTA@UiO-66 and UiO-66. Figure S3: PSDE of FA with IrEDTA complex onto the structure of FA_UiO-66. Figure S4: XRPD patterns of IrEDTA@UiO-66(3) before and after three catalytic runs. Figure S5: ${ }^{1} \mathrm{H}-\mathrm{NMR}$ spectrum of IrEDTA@UiO-66 after 3 catalytic runs.

Author Contributions: Conceptualization, F.C. and A.M.; methodology, F.C., F.M., A.M.; formal analysis, G.G., R.B. and F.M.; data curation, G.G., F.M. and F.C.; writing-original draft preparation, F.C. and A.M.; writing-review and editing, F.C. and A.M.

Funding: This research received no external funding.

Conflicts of Interest: The authors declare no conflict of interest.

\section{References}

1. Alstrum-Acevedo, J.H.; Brennaman, M.K.; Meyer, T.J. Chemical Approaches to Artificial Photosynthesis. 2. Inorg. Chem. 2005, 44, 6802-6827. [CrossRef] [PubMed]

2. Lewis, N.S.; Nocera, D.G. Powering the planet: Chemical challenges in solar energy utilization. Proc. Natl. Acad. Sci. USA 2006, 103, 15729-15735. [CrossRef] [PubMed]

3. Balzani, V.; Credi, A.; Venturi, M. Photochemical Conversion of Solar Energy. ChemSusChem 2008, 1, $26-58$. [CrossRef] [PubMed]

4. Llobet, A. Molecular Water Oxidation Catalysis: A Key Topic for New Sustainable Energy Conversion Schemes; Wiley-Interscience: New York, NY, USA, 2014.

5. Macchioni, A. The Middle-Earth between Homogeneous and Heterogeneous Catalysis in Water Oxidation with Iridium. Eur. J. Inorg. Chem. 2019, 2019, 7-17. [CrossRef]

6. Corbucci, I.; Macchioni, A.; Albrecht, M. Iridium Complexes in Water Oxidation Catalysis. In Iridium(III) in Optoelectronic and Photonics Applications; John Wiley \& Sons Ltd.: Hoboken, NJ, USA, 2017; pp. 617-654.

7. Thomsen, J.M.; Huang, D.L.; Crabtree, R.H.; Brudvig, G.W. Iridium-based complexes for water oxidation. Dalt. Trans. 2015, 44, 12452-12472. [CrossRef] [PubMed]

8. Menendez Rodriguez, G.; Bucci, A.; Hutchinson, R.; Bellachioma, G.; Zuccaccia, C.; Giovagnoli, S.; Idriss, H.; Macchioni, A. Extremely Active, Tunable, and pH-Responsive Iridium Water Oxidation Catalysts. ACS Energy Lett. 2017, 2, 105-110. [CrossRef]

9. Macchioni, A.; Menendez Rodriguez, G.; Gatto, G.; Zuccaccia, C. Benchmarking Water Oxidation Catalysts Based on Iridium Complexes: Clues and Doubts on the Nature of Active Species. ChemSusChem 2017, 4503-4509.

10. Michaelos, T.K.; Shopov, D.Y.; Sinha, S.B.; Sharninghausen, L.S.; Fisher, K.J.; Lant, H.M.C.; Crabtree, R.H.; Brudvig, G.W. A Pyridine Alkoxide Chelate Ligand That Promotes Both Unusually High Oxidation States and Water-Oxidation Catalysis. Accounts Chem. Res. 2017, 50, 952-959. [CrossRef] [PubMed]

11. Yang, K.R.; Matula, A.J.; Kwon, G.; Hong, J.; Sheehan, S.W.; Thomsen, J.M.; Brudvig, G.W.; Crabtree, R.H.; Tiede, D.M.; Chen, L.X.; et al. Solution Structures of Highly Active Molecular Ir Water-Oxidation Catalysts from Density Functional Theory Combined with High-Energy X-ray Scattering and EXAFS Spectroscopy. J. Am. Chem. Soc. 2016, 138, 5511-5514. [CrossRef] 
12. Woods, J.A.; Lalrempuia, R.; Petronilho, A.; McDaniel, N.D.; Müller-Bunz, H.; Albrecht, M.; Bernhard, S. Carbene iridium complexes for efficient water oxidation: Scope and mechanistic insights. Energy Environ. Sci. 2014, 7, 2316-2328. [CrossRef]

13. Venturini, A.; Barbieri, A.; Reek, J.N.H.; Hetterscheid, D.G.H. Catalytic Water Splitting with an Iridium Carbene Complex: A Theoretical Study. Chem. A Eur. J. 2014, 20, 5358-5368. [CrossRef] [PubMed]

14. McDaniel, N.D.; Coughlin, F.J.; Tinker, L.L.; Bernhard, S. Cyclometalated Iridium(III) Aquo Complexes: Efficient and Tunable Catalysts for the Homogeneous Oxidation of Water. J. Am. Chem. Soc. 2008, 130, 210-217. [CrossRef] [PubMed]

15. Li, M.; Takada, K.; Goldsmith, J.I.; Bernhard, S. Iridium(III) Bis-Pyridine-2-Sulfonamide Complexes as Efficient and Durable Catalysts for Homogeneous Water Oxidation. Inorg. Chem. 2016, 55, 518-526. [CrossRef] [PubMed]

16. Fagiolari, L.; Scafuri, A.; Costantino, F.; Vivani, R.; Nocchetti, M.; Macchioni, A. A Ternary Zn-Al-Ir Hydrotalcite-Like Compound Exhibiting High Efficiency and Recyclability as a Water Oxidation Catalyst. ChemPlusChem 2016, 81, 1060-1063. [CrossRef]

17. Wan, X.; Wang, L.; Dong, C.L.; Rodriguez, G.M.; Huang, Y.-C.; Macchioni, A.; Shen, S. Activating Kläui-Type Organometallic Precursors at Metal Oxide Surfaces for Enhanced Solar Water Oxidation. ACS Energy Lett. 2018, 3, 1613-1619. [CrossRef]

18. Sheehan, S.W.; Thomsen, J.M.; Hintermair, U.; Crabtree, R.H.; Brudvig, G.W.; Schmuttenmaer, C.A. A molecular catalyst for water oxidation that binds to metal oxide surfaces. Nat. Commun. 2015, 6. [CrossRef] [PubMed]

19. Chen, Z.; Concepcion, J.J.; Hu, X.; Yang, W.; Hoertz, P.G.; Meyer, T.J. Concerted O atom-proton transfer in the O-O bond forming step in water oxidation. Proc. Natl. Acad. Sci. USA 2010, 107, 7225-7229. [CrossRef] [PubMed]

20. Savini, A.; Bucci, A.; Nocchetti, M.; Vivani, R.; Idriss, H.; Macchioni, A. Activity and Recyclability of an Iridium-EDTA Water Oxidation Catalyst Immobilized onto Rutile $\mathrm{TiO}_{2}$. ACS Catal. 2015, 5, $264-271$. [CrossRef]

21. Pastori, G.; Wahab, K.; Bucci, A.; Bellachioma, G.; Zuccaccia, C.; Llorca, J.; Idriss, H.; Macchioni, A. Heterogenized Water Oxidation Catalysts Prepared by Immobilizing Kläui-Type Organometallic Precursors. Chem. A Eur. J. 2016, 22, 13459-13463. [CrossRef]

22. Materna, K.L.; Rudshteyn, B.; Brennan, B.J.; Kane, M.H.; Bloomfield, A.J.; Huang, D.L.; Shopov, D.Y.; Batista, V.S.; Crabtree, R.H.; Brudvig, G.W. Heterogenized Iridium Water-Oxidation Catalyst from a Silatrane Precursor. ACS Catal. 2016, 6, 5371-5377. [CrossRef]

23. Materna, K.L.; Crabtree, R.H.; Brudvig, G.W. Anchoring groups for photocatalytic water oxidation on metal oxide surfaces. Chem. Soc. Rev. 2017, 46, 6099-6110. [CrossRef] [PubMed]

24. Wang, C.; Xie, Z.; Dekrafft, K.E.; Lin, W. Doping Metal-Organic Frameworks for Water Oxidation, Carbon Dioxide Reduction, and Organic Photocatalysis. J. Am. Chem. Soc. 2011, 133, 13445-13454. [CrossRef]

25. Wang, C.; Wang, J.-L.; Lin, W. Elucidating Molecular Iridium Water Oxidation Catalysts Using Metal-Organic Frameworks: A Comprehensive Structural, Catalytic, Spectroscopic, and Kinetic Study. J. Am. Chem. Soc. 2012, 134, 19895-19908. [CrossRef]

26. Shao, Q.; Yang, J.; Huang, X. The Design of Water Oxidation Electrocatalysts from Nanoscale Metal-Organic Frameworks. Chem. A Eur. J. 2018, 24, 15143-15155. [CrossRef] [PubMed]

27. Adil, K.; Belmabkhout, Y.; Pillai, R.S.; Cadiau, A.; Bhatt, P.M.; Assen, A.H.; Maurin, G.; Eddaoudi, M. Gas/vapour separation using ultra-microporous metal-organic frameworks: Insights into the structure/separation relationship. Chem. Soc. Rev. 2017, 46, 3402-3430. [CrossRef] [PubMed]

28. Adil, K.; Chen, Z.; Weseliński, Ł.J.; Belmabkhout, Y.; Eddaoudi, M. A supermolecular building layer approach for gas separation and storage applications: The eea and rtl MOF platforms for $\mathrm{CO}_{2}$ capture and hydrocarbon separation. J. Mater. Chem. A 2015, 3, 6276-6281.

29. Escorihuela, J.; Narducci, R.; Compañ, V.; Costantino, F. Proton Conductivity of Composite Polyelectrolyte Membranes with Metal-Organic Frameworks for Fuel Cell Applications. Adv. Mater. Interfaces 2019, 6, 1801146. [CrossRef]

30. Wu, R.; Qian, X.; Zhou, K.; Liu, H.; Yadian, B.; Wei, J.; Zhu, H.; Huang, Y. Highly dispersed Au nanoparticles immobilized on Zr-based metal-organic frameworks as heterostructured catalyst for CO oxidation. J. Mater. Chem. A 2013, 1, 14294-14299. [CrossRef] 
31. Wu, H.; Chua, Y.S.; Krungleviciute, V.; Tyagi, M.; Chen, P.; Yildirim, T.; Zhou, W. Unusual and highly tunable missing-linker defects in zirconium metal-organic framework UiO-66 and their important effects on gas adsorption. J. Am. Chem. Soc. 2013, 135, 10525-10532. [CrossRef] [PubMed]

32. Vilela, S.M.F.; Tomé, J.P.C.; Silva, P.; Paz, F.A.A. Multifunctional metal-organic frameworks: From academia to industrial applications. Chem. Soc. Rev. 2015, 44, 6774-6803.

33. Cavka, J.H.; Jakobsen, S.; Olsbye, U.; Guillou, N.; Lamberti, C.; Bordiga, S.; Lillerud, K.P. A New Zirconium Inorganic Building Brick Forming Metal Organic Frameworks with Exceptional Stability. J. Am. Chem. Soc. 2008, 130, 13850-13851. [CrossRef] [PubMed]

34. Yang, D.; Odoh, S.O.; Wang, T.C.; Farha, O.K.; Hupp, J.T.; Cramer, C.J.; Gagliardi, L.; Gates, B.C. Metal-organic framework nodes as nearly ideal supports for molecular catalysts: NU-1000-and UiO-66-supported iridium complexes. J. Am. Chem. Soc. 2015, 137, 7391-7396. [CrossRef] [PubMed]

35. Yang, D.; Odoh, S.O.; Borycz, J.; Wang, T.C.; Farha, O.K.; Hupp, J.T.; Cramer, C.J.; Gagliardi, L.; Gates, B.C. Tuning Zr6 Metal-Organic Framework (MOF) Nodes as Catalyst Supports: Site Densities and Electron-Donor Properties Influence Molecular Iridium Complexes as Ethylene Conversion Catalysts. ACS Catal. 2016, 6, 235-247. [CrossRef]

36. Pintado-Sierra, M.; Rasero-Almansa, A.M.; Corma, A.; Iglesias, M.; Sanchez, F. Bifunctional iridium-(2-aminoterephthalate)-Zr-MOF chemoselective catalyst for the synthesis of secondary amines by one-pot three-step cascade reaction. J. Catal. 2013, 299, 137-145. [CrossRef]

37. Taddei, M. When defects turn into virtues: The curious case of zirconium-based metal-organic frameworks. Coord. Chem. Rev. 2017, 343, 1-24. [CrossRef]

38. Taddei, M.; Wakeham, R.J.; Koutsianos, A.; Andreoli, E.; Barron, A.R. Post-Synthetic Ligand Exchange in Zirconium-Based Metal-Organic Frameworks: Beware of The Defects! Angew. Chemie Int. Ed. 2018, 57, 11706-11710. [CrossRef] [PubMed]

39. Savini, A.; Bellachioma, G.; Bolaño, S.; Rocchigiani, L.; Zuccaccia, C.; Zuccaccia, D.; Macchioni, A. Iridium-EDTA as an Efficient and Readily Available Catalyst for Water Oxidation. ChemSusChem 2012, 5 , 1415-1419. [CrossRef] [PubMed]

40. De Stefano, M.R.; Islamoglu, T.; Garibay, S.J.; Hupp, J.T.; Farha, O.K. Room-temperature synthesis of UiO-66 and thermal modulation of densities of defect sites. Chem. Mater. 2017, 29, 1357-1361. [CrossRef]

41. Codolà, Z.; Gamba, I.; Acuña-Parés, F.; Casadevall, C.; Clémancey, M.; Latour, J.-M.; Luis, J.M.; Lloret-Fillol, J.; Costas, M. Design of Iron Coordination Complexes as Highly Active Homogenous Water Oxidation Catalysts by Deuteration of Oxidation-Sensitive Sites. J. Am. Chem. Soc. 2019, 141, 323-333. [CrossRef] [PubMed]

42. Zuccaccia, C.; Bellachioma, G.; Bortolini, O.; Bucci, A.; Savini, A.; Macchioni, A. Transformation of a Cp*-Iridium(III) Precatalyst for Water Oxidation when Exposed to Oxidative Stress. Chem. A Eur. J. 2014, 20, 3446-3456. [CrossRef] [PubMed]

43. Peters, W.S.; I Baskin, T. Tailor-made composite functions as tools in model choice: The case of sigmoidal vs bi-linear growth profiles. Plant Methods 2006, 2, 11. [CrossRef] [PubMed]

(C) 2019 by the authors. Licensee MDPI, Basel, Switzerland. This article is an open access article distributed under the terms and conditions of the Creative Commons Attribution (CC BY) license (http://creativecommons.org/licenses/by/4.0/). 